UP35 (continued)

a teacher/parent role-modeling curriculum) or (2) Control Arm $(\mathrm{N}=16)$.

Evaluation: Food behavior scale (factor) scores showed a significant change among intervention teachers (mean \pm SE: $0.32 \pm 0.15, \mathrm{p}=0.05)$ versus control-arm teachers (mean \pm SE: $0.08 \pm 0.14, \mathrm{p}=0.56$ ) over one school year. At 18-month month follow-up, there was a significant association between teacher change scores and student body mass index change scores for boys $(\beta \pm \mathrm{SE}: 0.34 \pm 0.15$ $\mathrm{p}=0.02$ ).

Conclusions and Implications: Teacher role-modeling can influence healthy nutrition intake and normal weight gain during early childhood.

Funding: USDA Grant \#2009-05065.

\section{UP36 Interventions for Obesity Prevention Targeting Young Children in At-risk Environments: An Integrated Approach}

Rodolfo Nayga, Jr., PhD, rnayga@uark.edu, University of Arkansas Division of Agriculture, Department of Agricultural Economics \& Agribusiness, 217 Agriculture Building University of Arkansas, Fayetteville, AR 72701; M. Thomsen, PhD; E. Howlett, PhD, University of Arkansas, Sam M. Walton College of Business; H. Rouse, PhD, Arkansas Center for Health Improvement; J. Weber, PhD, $R D$, Arkansas Children's Hospital Research Institute; L. Whiteside-Mansell, EdD, University of Arkansas for Medical Sciences

Objective: To improve the diets of young children, reinforce healthy diet and exercise behaviors, and improve understanding of the causes of childhood obesity.

Description: We are assessing (1) factors that place children at risk for obesity; (2) social marketing messages; and (3) feasibility of a farm-to-school network. Programing is being developed for Head Start and early elementary classrooms and also for students in higher education.

Evaluation: Evaluations addressed linkages between obesity outcomes and the built and home environment and also early phases of the educational, farm-to-school, and social marketing interventions.

Conclusions and Implications: Findings will guide development of programming and policies to combat childhood obesity.

Funding: USDA Grant \#2011-68001-30014.

\section{UP37 Basic Culinary and Cooking Skills: Pilot Testing of a Hands-on Intervention}

Sharon M. Nickols-Richardson,PhD, RD, smn13@psu.edu, Pennsylvania State University, 110 Chandlee Laboratory, Department of Nutritional Sciences, University Park, PA 16802; S. A. Nelson, BS; M. G. Graziose, BS; K. M. Scoular, BS; M. A. Corbin, PhD

Objective: To evaluate a nutrition education intervention on culinary skills using formative, process and outcome measurements.
Description: Two 2-hour hands-on education lessons, developed for 11- to 14-year-olds, were pilot tested with 8 females. Lessons taught participants how to perform basic knife and cooking skills for preparing fruits and vegetables.

Evaluation: Focus groups were conducted after each lesson, and process measures were evaluated as well as outcome assessments.

Conclusions and Implications: Participants were highly satisfied with both culinary lessons. In a group of 11- to 14-year-old females, self-reported knowledge and self-efficacy for cutting and cooking fruits and vegetables increased as did self-reported preference for fruits and vegetables.

Funding: USDA Grant \#2012-68001-19652.

\section{UP38 Family Menu Planning: Pilot Testing of an Interactive Nutrition Education Intervention}

Sharon M. Nickols-Richardson,PhD,RD, smn13@psu.edu, Pennsylvania State University, 110 Chandlee Laboratory, Department of Nutritional Sciences, University Park, PA 16802; S. A. Nelson, BS; M. G. Graziose, BS; K. M. Scoular, BS; M. A. Corbin, PhD

Objective: To evaluate a nutrition education intervention on family menu planning, using formative, process and outcome measurements.

Description: A 2-hour interactive educational session, created for 11-14 year-olds, was pilot tested with 8 females. The lesson focused on four elements: 1) planning nutritious meals, using principles of Dietary Guidelines for Americans, 2010; 2) creating family menu schedules; 3) preparing for away-from-home meals, and 4) building costefficient grocery shopping lists.

Evaluation: Focus groups with participants were conducted and process measures were evaluated along with outcome assessments.

Conclusions and Implications: A group of young adolescent females were highly satisfied with the intervention and increased self-efficacy for family menu planning.

Funding: USDA Grant \#2012-68001-19652.

\section{UP39 Mobilizing Rural Low-Income Communities to Assess and Improve the Ecological Environment}

Paula Peters, PhD, ppeters@ksu.edu, Kansas State University, 340 Justin Hall, Manhattan, KS 66503; A. R. Mobley, PhD, Purdue University; S. Procter, PhD, RD, Kansas State University; $D$. Contreras, $P h D$, Michigan State University; A. L. Gold, PhD, North Dakota State University; K. Bruns, PhD, Ohio State University; R. Oscarson, PhD, South Dakota State University; A. Keim, PhD, University of Wisconsin

Objective: Enhance capacity of rural, low-income communities to prevent childhood obesity. 